\title{
The autologous fascia pubovaginal sling for complicated female stress incontinence
}

\author{
Blayne K. Welk, MD, FRCSC; Sender Herschorn, BSC, MDCM, FRCSC
}

Sunnybrook Hospital, Division of Urology, University of Toronto, Toronto, ON

See related article on page 41 .

Cite as: Can Urol Assoc J 2012;6(1):36-40. htrp://dx.doi.org/10.5489/cuaj.11117

\section{Abstract}

Introduction: The purpose of this study is to review our contemporary experience with autologous fascia pubovaginal slings (AF-PVS) in the era of the midurethral sling.

Methods: A retrospective review was completed to identify all patients who underwent an AF-PVS between 2002 and 2009. A cross-sectional questionnaire was used to assess postoperative urinary-specific quality of life (consisting of the Urogenital Distress Inventory [UDI-6] and the Incontinence Impact Questionnaires [IIQ-7]).

Results: We identified 33 patients. They had failed a median of two previous incontinence treatments. Of these patients, 16 (48\%) had failed a previous midurethral sling, and of these half had experienced a significant mesh erosion necessitating mesh removal. Preoperative median incontinence pad usage was 5/day. After a median follow-up of 16 months from the time of AF-PVS, the median pad usage had decreased to $1 /$ day $(p=0.003)$. A third of the patients had postoperative urgency, and only 1 patient continues to use intermittent catheterization. The median IIQ-7 score was $19 / 100$, and the median UDI- 6 score was $44 / 100$. Overall quality of life was mixed-to-delighted in $62 \%$ of patients.

Conclusions: The AF-PVS has reasonable outcomes in a diverse population of patients, despite failure of other treatment modalities.

\section{Introduction}

The surgical treatment of female stress urinary incontinence (SUI) has evolved over the last century with many treatments transitioning in and out of mainstream use. These include pubovaginal slings, retropubic suspensions, transvaginal urethral suspensions, urethral bulking agents and, most recently, mid-urethral slings (MUS). The autologous rectus fascia pubovaginal sling (AF-PVS) was described in the early 20th century and was brought into popular use again by McGuire in the late 1970s. ${ }^{1}$ The use of AF-PVS for SUI has excellent reported success rates. ${ }^{2}$

The surgical techniques for the placement of synthetic MUS are well-described; the procedures are safe and have long-term efficacy. ${ }^{3}$ The acceptance of the MUS has lead to the AF-PVS being reserved for "a fixed urethra with an open bladder neck, mixed incontinence, urethral reconstruction procedures, and following failed anti-incontinence procedures." ${ }^{\prime 4}$ The objective of this study was to characterize the patient population that receives an AF-PVS in the era of the MUS, and their continence outcomes.

\section{Methods}

Consecutive patients who had an AF-PVS procedure (by a single surgeon, $(\mathrm{SH})$ between 2002 and 2009 were identified retrospectively using hospital operative records. Patients with a neurogenic bladder were excluded. A total of 33 patients were identified; their medical records were reviewed, and their demographic, urodynamic and follow-up data were extracted.

Physical exam for all patients included an assessment of urethral hypermobility. Preoperative multichannel videourodynamics were performed using two 8-French feeding tubes and a rectal catheter (Laborie Systems, Toronto, ON). Results were available for 29 patients (4 patients were unable to hold any infused fluid due to the degree of incontinence, and therefore the urodynamic study was not completed).

The surgical technique is similar to that described in the literature. ${ }^{1,5}$ The bladder neck was exposed transvaginally. The endopelvic fascia was perforated and blunt dissection was used to develop the retropubic space up to the abdominal wall. A 5- 6-cm Pfannenstiel incision was used to harvest a strip of rectus fascia $10 \mathrm{~cm} \times 2 \mathrm{~cm}$, and a $\# 1$ prolene suture passed through either end. The fascial incision was closed, and a Raz-Peyera needle was passed from the abdominal 
incision into the retropubic space and guided through to the vaginal incisions. The prolene sutures, placed through the needle eyes, were pulled up into the abdominal incision. Cystoscopy was performed to ensure there was no injury to the bladder or urethra. The sling was sutured in place in the midline to the bladder neck, and then the prolene sutures were tied with no tension over the rectus fascia. Incisions were closed using absorbable sutures, and a Foley catheter was left in place.

Follow-up included history, physical exam and post-void residual (PVR). Patients were generally seen in follow-up at 6 weeks, 3 months, and then annually. Physician-assessed success was based on a patient-reported pad use of $\leq 1$ per day. Patients were contacted by mail with a request to complete the short form of the Urogenital Distress Index (UDI-6) and the Incontinence Impact Questionnaires (IIQ-7). Both questionnaires have been validated as specific-urinary quality of life (QOL) measures. ${ }^{6,7}$ The patient's global urinary QOL was assessed with the American Urological Association symptom score QOL question (which uses a Likert scale of 1 [terrible] to 7 [delighted]), and their current incontinence pad usage (if any) was elicited.

\section{Data analysis and presentation}

The original IIQ-7 score out of 21 points and the UDI-6 score out of 18 points were rescaled from 0 to 100; a higher score represents worse QOL. Using a two-sided alpha $=0.05$ and a beta $=0.20$, we required 25 patients to detect an effect size of 0.8 in person pad usage. Categorical variables are presented as percentage (number of patients). Continuous and ordinal variables are presented as median (interquartile range). Patient's change in pad per day (PPD) usage or PVR from preoperative to last follow-up was compared with the Wilcoxon signed-rank test. The Spearman rank correlation coefficient was used to assess correlation between the UDI-6, IIQ-7, overall QOL and physician assessment $(r=0$ means no correlation, $r=1$ means perfect correlation). Two sided $p$ values are reported, and $p<0.05$ was considered significant. We used SAS 9.2 (SAS Institute, Cary, NC) for our statistical analysis.

\section{Results}

Thirty-three women with a median age of 57 (range: 48-64) were part of the total study population (Table 1). Etiology of the incontinence was considered complex in 18 patients: 10 had symptomatic urethral, bladder or vaginal mesh erosions, 2 had a urethral diverticulectomy, 2 had pelvic fractures, 2 had iatrogenic urethral injuries, 1 had previous pelvic radiation, and 1 had obstetrical trauma. Patients with mesh erosions were treated with an initial surgery to remove the eroded mesh, and then a subsequent operation for the

\begin{tabular}{lc}
\hline \multicolumn{2}{l}{ Table 1. Baseline characteristics and previous incontinence } \\
procedures & All patients \\
\hline & 33 \\
\hline No. patients & 57 (IQR: $48-64)$ \\
Age (years) & 5 (IQR:4-7) \\
Self-reported preoperative PPD & $24 \%$ \\
Patients with concomitant pelvic floor surgery & 2 (IQR: $1-3)$ \\
No. previous procedures & $45 \%$ \\
Previous MUS & $15 \%$ \\
Previous PVS & $30 \%$ \\
Previous mesh erosion & $48 \%$ \\
Previous burch colposuspension & $33 \%$ \\
Previous bulking procedure & \\
\hline PPD: pad per day usage; MUS: midurethral sling; PVS: pubovaginal sling; IOR: interquartile \\
range.
\end{tabular}

AF-PVS. Among the erosion patients, 6 were MUS urethral erosions and 2 were MUS vaginal erosions. There were two erosions due to previous synthetic bladder neck slings ( 1 eroded into the bladder and 1 into the vagina). All of these patients with previous erosions had periurethral fibrosis from the mesh erosion and subsequent resection of the mesh; this was the likely cause of their urethral immobility, and the reason they received an AF-PVS. The remaining 15 patients had persistent or recurrent SUI despite multiple procedures.

In the entire group of 33 women, the median self-reported preoperative level of incontinence was 5 (range: 4-7) PPD. Physical exam demonstrated no significant hypermobility, which was the primary reason for selected an AF-PVS. A median of 2 (range: $1-3$ ) previous procedures to treat SUI had been attempted, and a median of 2 (range: 1-2) previous treatment modalities had been attempted (such as bulking agents, midurethral tapes, bladder neck slings and retropubic suspensions). Two patients had an AF-PVS preformed as their first SUI procedure (1 had a previous urethral diverticulectomy and the other had external pelvic trauma and a urethrovaginal fistula). Eight patients had concomitant pelvic floor/ reconstructive surgery with their AF-PVS, such as rectocele/ cystocele repairs, urethral reconstruction, urethral diverticulectomy and repair of urethro- or vesicovaginal fistulas.

The preoperative urodynamics results of 29 patients were available (Table 2). Median PVR was 10 (range: 0-40) mL. Two patients had reduced compliance and 7 had idiopathic detrusor overactivity. Valsalva leak-point pressures (VLPP) were assessed at capacity. Median VLPP was 86 (range: 73-107) $\mathrm{cmH} 2 \mathrm{O}$; 4 patients had VLPP $<60 \mathrm{cmH} 2 \mathrm{O}, 12$ had VLPP 60 to $90 \mathrm{cmH} 2 \mathrm{O}$, and 13 patients had VLPP $>90 \mathrm{cmH} 2 \mathrm{O}$.

The median length of stay for the patients was 2 (range: 1-3) days. No patients required blood transfusions or a repeat operation within 30 days. Perioperative complications were all Clavien Class $I^{8}$ and were noted in $15 \%$ (5) of patients. There were 2 patients with abdominal wound infections 


\begin{tabular}{lc}
\hline \multicolumn{2}{l}{ Table 2. Preoperative urodynamic assessment } \\
\hline \multicolumn{2}{c}{ All patients } \\
\hline No. patients & 29 \\
PVR $(\mathrm{mL})$ & 10 (IQR: $0-40)$ \\
Volume at first sensation $(\mathrm{mL})$ & 110 (IQR: 74-175) \\
Volume at desire to void $(\mathrm{mL})$ & 217 (IQR: $120-340)$ \\
Capacity $(\mathrm{mL})$ & 368 (IQR: $320-503)$ \\
Reduced compliance & $7 \%$ \\
Detrusor overactivity & $24 \%$ \\
Valsalva LPP $\left(\mathrm{cmH}_{2} 0\right)$ & 86 (IQR: $73-107)$ \\
Qmax (mL/sec) & 20 (IQR: $15-25)$ \\
Previous bulking procedure & $33 \%$ \\
\hline
\end{tabular}

PVR: postvoid residual; LPP: leak-point pressure; Omax: maximum flow rate; IQR: interquartile range.

which were treated with oral antibiotics, and there was 1 patient who developed a superficial wound infection which required packing. There were 2 patients with symptomatic abdominal seromas which were treated conservatively, and 1 person who returned to the emergency room with incisional pain which was treated with oral analgesics.

Patients had a median follow-up of 16 (range: 13-39) months (Table 3). Median pad use for the entire group had decreased significantly from preoperative pad use of 5 to 1 PPD ( $p=0.003)$. Overall physician-assessed success from the last clinic follow-up was $64 \%$. The median PVR was 32 (range: $0-68) \mathrm{mL}$, and was not significantly different from preoperative values $(p=0.22)$. Three patients had PVRs $>100 \mathrm{~mL}$ at their most recent follow-up. Two were asymptomatic from this, and 1 continued to use intermittent catheterization. Of the 5 patients who required intermittent catheterization, 4 were able to resume spontaneous voiding 3 to 9 months after surgery. Urinary urgency was assessed during the clinic follow-up visits, and identified as a concern in $33 \%$ of patients, all of whom were offered a trial of anticholinergics. Only 2 of the 7 patients with preoperative detrusor overactivity had symptomatic postoperative urgency. There were no postoperative urethral strictures.

The survey response rate was $64 \%$ (21/33 patients). For the entire group of patients with an AF-PVS, the median UDI-6 score was 44 (range: 22-55), and the median IIQ-7 score was 19 (range: 0-52). The median overall QOL was 4 (mixed). There was statistically significant correlation $(p<0.001)$ between the IIQ-7 and UDI-6 scores $(r=0.80)$ and between the overall QOL and the UDI-6 $(r=0.72)$ and IIQ-7 $(r=0.84)$. Physician observed success had a modest significant correlation $(p<0.001)$ with the UDI-6 $(r=0.59)$, IIQ-7 $(r=0.73)$ and overall QOL $(r=0.57)$. Postoperative pad usage had a significant correlation $(p<0.001)$ with the UDI-6 $(r=0.71)$, the IIQ-7 $(r=0.85)$ and the overall QOL $(r=0.84)$. The VLPP did not have a significant correlation ( $p>0.05$ ) with preoperative pad use, physician-observed success or any of the QOL measures.

\section{Discussion}

Data from the United States National Hospital Discharge Survey from 1979 to 2004 demonstrated an increase in the use of the MUS and a decrease in PVS. ${ }^{9}$ Overall, the number of procedures for SUI has increased significantly, especially in older women. The most likely reason for this increase is the simplicity and reduced morbidity of the MUS compared to previous incontinence treatment modalities, such as the AF-PVS.

This increase in the use of the MUS seems appropriate given the available evidence. Similar intermediate term success rates have been reported for the transvaginal tape (TVT) $\left(86 \%\right.$ at 3 years $\left.^{10}\right)$ and the AF-PVS $\left(92 \%\right.$ at 3 years $\left.{ }^{2}\right)$. Sharifiaghdas and Mortazavi randomized 100 women to either TVT or AF-PVS and followed them for a mean period of 3 years. ${ }^{11}$ Objective cure rates using the 1 -hour pad test were similar in the TVT $(76 \%)$ and AF-PVS (72\%) groups. The long-term cure rates also appear similar, with estimates of 7 -year cure rates of $59 \%$ for the AF-PVS and $55 \%$ for the TVT. ${ }^{12}$

As the MUS seems to have supplanted the AF-PVS, we addressed the contemporary use and outcomes of the AF-PVS. The population in this paper is extremely challenging, with patients failing other treatment modalities, and suffering extensive trauma to their urethras. The patients were all similar in that they had significant incontinence and fixed, immobile urethras on physical exam. We did not find that the VLPP was associated with eventual success of the AF-PVS (similar to other studies ${ }^{13}$ ). The lack of a stan-

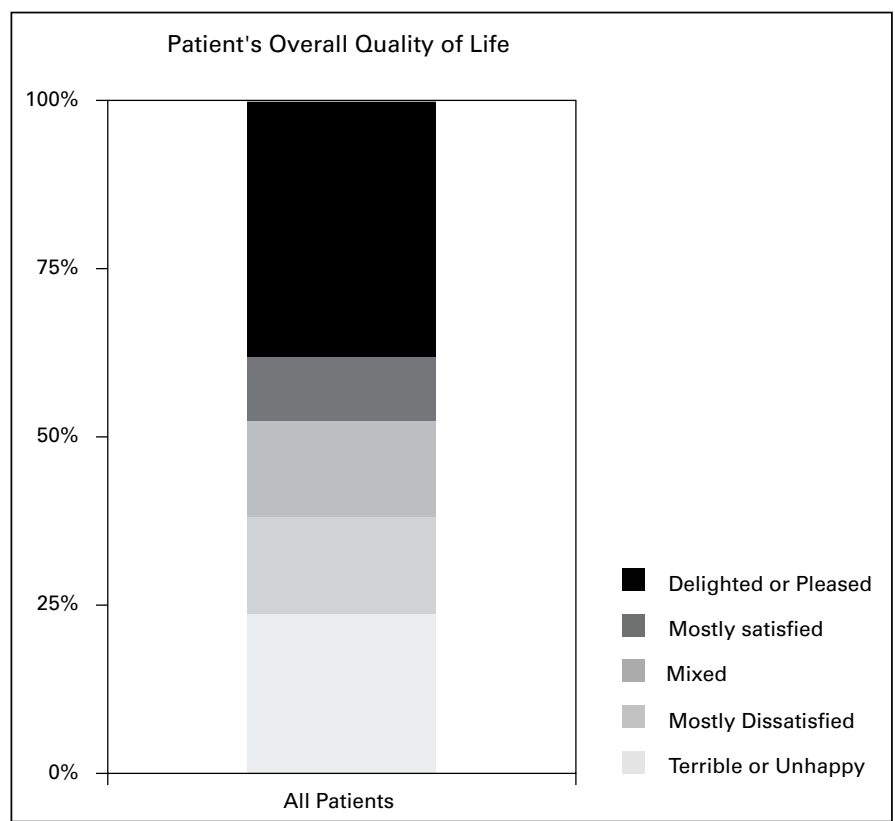

Fig. 1. Overall quality of life score, (global assessment question from the American Urological Association symptom score). 


\begin{tabular}{lc}
\hline $\begin{array}{l}\text { Table 3. Patient outcomes at last clinic visit and quality of } \\
\text { life assessment from the cross-sectional questionnaire }\end{array}$ \\
\hline & All patients \\
\hline Follow-up (months) & 16 (IQR: 13-39) \\
PVR at last follow-up (mL) & 32 (IQR: 0-68) \\
Any use of CIC Required & $17 \%$ \\
Self-reported urgency & $33 \%$ \\
Self-reported pad per day usage & 1 (IQR: $0-5)$ \\
Physician assessed success & $64 \%$ \\
Questionnaire response rate & $64 \%$ \\
Total UDI-6 Score & 44 (IQR: $22-55)$ \\
Total IIQ-7 Score & 19 (IQR: 0-52) \\
Overall quality of life & 4 (IQR: 3-7) \\
\hline PVR: postvoid residual; CIC: clean intermittent catheterization; UDI: Urogenital Distress \\
index; IOR: interquartile range.
\end{tabular}

dard technique for obtaining VLPPs is one of the reasons for the wide range of values seen in our patients. ${ }^{13}$ There was a significant reduction in median pad usage from 5 PPD preoperatively to 1 PPD postoperatively; this represents a considerable improvement in continence. Overall success of the AF-PVS was assessed by the physician at last followup (64\% success) and by the patient's overall QOL rating (62\% scored from 4 mixed] to 7 [delighted]) at a median of 16 months. This is similar to the reported success rates of $59 \%$ to $93 \% .^{12,14-16}$ However, it is difficult to compare across series due to the variability in defining success and the heterogeneous populations. Chaikin and colleagues published a cured/improved success rate of $92 \%$ at a median 3 years follow-up for 251 patients. ${ }^{2}$ A subsequent series by Flisser and Blaivas of 74 women undergoing urethral reconstruction included 56 who had a concomitant AF-PVS; $87 \%$ were cured/improved in terms of SUI. ${ }^{14}$ Morgan and colleagues published a series of 247 women who received an AF-PVS; their self-reported continence rate was $88 \%$ at a mean follow-up of 4 years. ${ }^{15}$ Our series consists largely of patients with fixed immobile and traumatized urethras. This may explain the lower success rate we observed compared to previous studies. Other series of complex patients are similar to our results; Pertrou and Frank reported a 50\% cure rate in 14 patients who had a repeat AF-PVS after failing their initial PVS. ${ }^{17}$ Migliari and colleagues reported an SUI cure rate of $80 \%$ in 32 women treated with AF-PVS performed at the time of urethral diverticulum repair. ${ }^{18}$

Complications associated with the AF-PVS have been well-described in the literature. Rates of symptomatic urgency range from $7 \%$ to $20 \%$, and the need for postoperative intermittent catheterization at 1 month varies from $6 \%$ to $47 \%$. ${ }^{12,14,15,19}$ We found that $33 \%$ of our patients had postoperative urgency that bothered them enough to try anticholinergic medication. Our rate of postoperative intermittent catheterization was $17 \%$, with only 1 patient $(3 \%)$ continuing clean intermittent catheterization (CIC) after 1 year.

Perhaps more important is the patient's own perception of cure. The UDI-6 and IIQ-7 have been used extensively in evaluating incontinence domains in women. We found a median UDI-6 score of 44 (range: $22-55$ ) and a median IIQ-7 score of 19 (range: 0-52). In trying to define success after incontinence surgery, Rapp and Kobashi found a mean UDI-6 score of 28, and an IIQ-7 score of 14 in a group of 74 women after AF-PVS, with the majority having $>12$ months follow-up..$^{20}$ The details of the patient population receiving AF-PVS was unavailable. The higher UDI-6 and IIQ-7 scores identified in this study population as a whole are in keeping with our success rate; their relatively modest correlation with physician observed success underscores the complexity of evaluating outcomes in these patients, and the broad impact of incontinence on health-related QOL. ${ }^{21}$ As expected, pad usage was significantly correlated with urinary specific QOL.

This study is limited by its modest number of patients and intermediate-term follow-up. The retrospective nature of the study also limited the variables we were able to retrieve from the medical records. Although both the proportion of successful patients among questionnaire non-responders $(25 \%)$ and responders (33\%), and the median follow-up time (13 months and 16 months, respectively) was similar, our questionnaire response rate may be associated with a degree of selection bias. We do not have a preoperative IIQ-7 and UDI-6 score to compare to, therefore we cannot comment objectively on an improvement in incontinence related QOL after an AF-PVS.

\section{Conclusion}

The AF-PVS can be used to salvage difficult SUI cases. The outcomes in this challenging patient group are reasonable, with a successful outcome in about two thirds of patients. There were no serious perioperative complications. The AF-PVS lead to a significant reduction in the number of incontinence pads used per day; $33 \%$ of patients experienced urinary urgency and 3\% (1 patient) required prolonged $\mathrm{CIC}$. The incontinence-related QOL of these patients was measured with the UDI-6 and IIQ-7, and the median scores are reasonable given their preoperative incontinence.

Competing interests: Dr. Herschorn has received frant funding for clinical trials from Astellas, Pfizer, American Medical Systems, Allergan, and Contura. He is also on the advisory boards for Pfizer, Allergan, Astellas and American Medical Systems. He has received speaker fees from Astellas, Pfizer, American Medical Systems.

This paper has been peer-reviewed.

\section{References}

1. McGuire EJ, Lytton B. Pubovaginal sling for stress incontinence. J Urol 1978;119:82-4.

2. Chaikin DC, Rosenthal J, Blaivas JG. Pubovaginal fascial sling for all types of stress urinary incontinence: long term analysis. J Urol 1998;160:1312-6. http://dx.doi.org/10.1016/S0022-5347(01)62524-2 
Welk and Herschorn

3. Rapp DE, Kobashi KC. The evolution of midurethral slings. Nat Clin Pract Urol 2008;5:194-201.

4. Wilson WJ, Winters IC. Is there still a place for the pubovaginal sling at the bladder neck in the era of the midurethral sling? Curr Urol Rep 2005;6:335-9. http://dx.doi.org/10.1007/s1 1934-005-0049-7

5. Blaivas $J G$, Chaikin $D C$. Pubovaginal fascial sling for the treatment of all types of stress urinary incontinence: surgical technique and long-term outcome. Urol Clin North Am 2011;38:7-15. http://dx.doi. org/10.1016/i.ucl.2010.12.002

6. Shumaker SA, Wyman JF, Uebersax JS, et al. Health-related quality of life measures for women with urinary incontinence: the Incontinence Impact Questionnaire and the Urogenital Distress Inventory. Continence Program in Women (CPW) Research Group. Qual Life Res 1994;3:291-306. http://dx.doi. org/10.1007/BF00451721

7. Uebersax JS, Wyman JF, Shumaker SA, et al. Short forms to assess life quality and symptom distress for urinary incontinence in women: the Incontinence Impact Questionnaire and the Urogenital Distress Inventory. Continence Program for Women Research Group. Neurourol Urodyn 1995;14:131-9. http:// dx.doi.org/10.1002/nau.1930140206

8. Dindo D, Demartines N, Clavien PA. Classification of surgical complications: a new proposal with evaluation in a cohort of 6336 patients and results of a survey. Ann Surg 2004;240:205-13. http://dx.doi. org/10.1097/01.sla.0000133083.54934.ae

9. Oliphant SS, Wang L, Bunker $\mathrm{CH}$, et al. Trends in stress urinary incontinence inpatient procedures in the United States, 1979-2004. Am J Obstet Gynecol 2009;200:521.e1-e6.

10. Ulmsten U, Johnson P, Rezapour M. A three year followup of tension free vaginal tape for surgical treatment of female stress urinary incontinence. Br J Obstet Gynaecol 1999;106:345-50. http://dx.doi. org/10.1111/i.1471-0528.1999.tb08272.11

11. Sharifiaghdas F, Mortazavi N. Tension-Free vaginal tape and autologous rectus fascia pubovaginal sling for the treatment of urinary stress incontinence: a medium term follow-up. Med Princ Pract 2008; 17:209-14. http://dx.doi.org/10.1159/000117794

12. Jeon MJ, Jung HJ, Chung SM, et al. Comparison of the treatment outcome of pubovaginal sling, tensionfree vaginal tape, and transobturator tape for stress urinary incontinence with intrinsic sphincter deficiency. Am J Obstet Gynecol 2008;199:76.el-e4.
13. Lemack GE. Urodynamic assessment of patients with stress incontinence: how effective are urethral pressure profilometry and abdominal leak point pressures at case selection and predicting outcome? Curr Opin Urol 2004;14:307-11. http://dx.doi.org/10.1097/00042307-200411000-00002

14. Flisser AJ, Blaivas JG. Outcome of urethral reconstructive surgery in a series of 74 women. J Urol 2003;169:2246-9. http://dx.doi.org/10.1097/01.ju.0000061763.88247.16

15. Morgan TOJ, Westney OL, MGGuire EJ. Pubovaginal sling: 4-YEAR outcome analysis and quality of life assessment. J Urol 2000;163:1845-8. http://dx.doi.org/10.1016/S0022-5347(05)67557-X

16. Reichelt 0 , Weirich $\mathrm{T}$, Wunderlich $\mathrm{H}$, et al. Pubovaginal cutaneous fascial sling procedure for stress urinary incontinence: 10 years' experience. Urol Int 2004;72:318-23. http://dx.doi.org/10.1159/000077685

17. Petrou SP, Frank I. Complications and initial continence rates after a repeat pubovaginal sling procedure for recurrent stress urinary incontinence. J Urol 2001;165:1979-81. http://dx.doi.org/10.1016/S0022$5347(05) 66257-X$

18. Migliari R, Pistolesi D, $D^{\prime} U r s 0 \mathrm{~L}$, et al. Recurrent pseudodiverticula of female urethra: five-year experience. Urology 2009;73:1218-22. http://dx.doi.org/10.1016/i.urology.2008.07.040

19. Morgan DM, Dunn RL, Fenner DE, et al. Comparative analysis of urinary incontinence severity after autologous fascia pubovaginal sling, pubovaginal sling and tension-free vaginal tape. J Urol 2007;177:604-8. http://dx.doi.org/10.1016/i.juro.2006.09.062

20. Rapp DE, Kobashi KC. Outcomes following sling surgery: importance of definition of success. J Urol 2008;180:998-1002. http://dx.doi.org/10.1016/i.juro.2008.05.043

21. Gil KM, Somerville AM, Cichowski S, et al. Distress and quality of life characteristics associated with seeking surgical treatment for stress urinary incontinence. Health Qual Life Outcomes 2009;7:8. http://dx.doi. org/10.1186/1477-7525-7-8

Correspondence: Dr. Blayne Welk, Division of Urology, Sunnybrook Health Science Centre, 2075 Bayview Avenue, Suite MG408, Toronto, ON M4N 3M5; bkwelk@gmail.com 